\title{
Developing Integrated Real-life Video and Animation (IRVA) for Physics based on Constructivism with ADDIE model
}

\author{
Silka Abyadati \\ Physics Program, School of Postgraduate Studies \\ Indonesia University of Education, Setiabudhi St, No.229 \\ Bandung, West Java, 40154 \\ Email: silkaabyadati@yahoo.com
}

\author{
Dadi Rusdiana \\ Physics Education Department \\ Indonesia University of Education, Setiabudhi St, No.229 \\ Bandung, West Java, 40154
}

\author{
Enjang A.Juanda \\ Electrical Engineering Education Department \\ Indonesia University of Education, Setiabudhi St, No.229 \\ Bandung, West Java, 40154
}

\begin{abstract}
Learning Physics still felt quite hard because containing an abstract concept and impressed have a lot of formula. Eventough the abstract concept actually relates with a daily life phenomena. Therefore it's needed an Integrated Reallife Video and Animation (IRVA) as a media that can be helpful for Physics learning process. The development of IRVA uses Analysis, Design, Development, Implementation, Evaluation (ADDIE) based on constructivist learning model: Interpretation Construction. From the experts judgement results $(95.48 \%)$, usability test result $(95.83 \%)$, and limited implementation to the student $(93.43 \%)$, IRVA developed according to media learning development principles. Moreover, the findings show that IRVA can be categorized as feasible as the media for Physics learning based constructivist.
\end{abstract}

Keywords-integrated real-life video and animation; constructivism; ADDIE

\section{INTRODUCTION}

Information and Communication Technology (ICT) implementation is one of an important aspect among the others, like: lesson subject, $21^{\text {st }}$ Century Learning themes and innovation [1]. The education sector is a sector that requires the presence of ICT to assist the course activity. American Association of Colleges of Teacher Education [2] states the use of technology in learning serves as a tool to research, organize, evaluate and communicate the information.

In terms of information communication, technology aided by computer devices can provide a deeper explanation about the abstract concept. Physics as a branch of Natural Sciences containing some abstract concepts related to everyday life. Some previous researchs have been done [3][4][5] showed that a visual media, aided by computer devices, can improve the quality of Physics teaching and learning process. The application of visual media can help teachers to deliver the subject matter as well as for the students to understand the concepts that are presented. Besides, people will learn more deeply with the help of pictures than from words alone. Pictures can include static graphic (illustrations or photos) or dynamic graphics (animation or video clips) [6].

However, by using video and animation as a learning media in the classroom, that's not just aim to full fill the learning needs in a formal way, but also should consider the material content as well as students' active role in accepting the media massage [7]. Video and animation is not tool for substitute a teacher, students need specific instruction to watch which part of the media have to be observe and what to do after they watched a video or animation. Teachers can ask students to observe, to answer the questions, to analyze the phenomenon to make predictions, and to interpret the messages that presented through the video and animation. At the end, video and animation need to be designed according to the purpose of learning in order to provide effectiveness in the process of classroom pedagogy [8]

Video and animation that have been developed are still standing separately. Video can present a real phenomenon in a daily life, but not equipped with physical conditions. Similarly, the animation can help students to have an illustration of Physics' physical condition, but still can't present a real impression in a daily life. Bell \& Bull stated that the digital video can contains images with narration and music, Flash animations, as well as a computer display recording/screen cast.

One of development designs for computer assisted media is using ADDIE model which has a stages: Analysis (determining what material will be studied), Design (specification of how material can be studied), Development (developing the media), Implementation (application of media in a real life) and Evaluation (assessment and decision on the outcome of media )[9][10].

From the results of field studies, the students' final score of Rotation Dynamics topic still show a less score (under the 
standard score of 75). Imfact, to master the concept of Dynamic Rotation can't just be done by memorizing formulas, it requires the ability to analyze the physical condition or the forces acting on the rotating object events [11]. The phenomenon in everyday life related to material Rotation Dynamics, indeed can be demonstrated directly, but it took much longer, especially to coverage the material that pretty complex. The abstract term of dynamics Rotation is a component magnitudes that can not appear when only communicated verbally or through demonstrations. For analysis purposes, the demonstration activities can not be able to present a phenomenon if there is a changing certain variables happens. Trunk rotation movement, for example, when given different weights will be rotate with different acceleration too. It does not appear to move different when only seen through direct observation. The phenomenon can be seen differently when recorded and showed video recordings simultaneously.

With the help of video, students will know the application of concepts of Physics in everyday life. This stimulates the imagination of students to look for other similar examples. Fadei (et.al) suggests that this could be a good method to enhance student learning in physics[12]. By demonstrating the phenomenon in everyday life will encourage students to think that being a Physicist does not always have to begin with a background of formulas and theories. On the other hand, with the development of technology and 'electronic lifestyle', the use of computer devices will provide experiences for students that Physics can be learned with multimedia facilities. With this step, the student can be given structured tasks that they can answer after watching media.

Although video-assisted learning, it does not eliminate it's terms of Physics learning constructivist student-centered. One of the constructivist learning model is the Interpretation Construction (ICON)[13]. ICON learning model that has been adapted [14] have eight stages: a) Observation; b) Construction Interpretation; c) Contextualization; d) Cognitive conflict; e) Cognitive apprenticeship; f) Collaboration; g) Multiple interpretation; h) Multiple Manifestation. This learning model can be adapted in a learning process to construct students' knowledge. Some steps can be integrated with media of video or animation to encourage students' activity. The development of Integrated Real-life Video and Animation (IRVA) is aim to facilitate students to construct their concept of Rotation. IRVA development uses ADDIE model, based on the national curriculum needs and constructivist learning model.

\section{RESEARCH METHOD}

IRVA development refers to the ADDIE models. The analysis phase done by assessing the needs of the curriculum and the expected cognitive ability. IRVA's design adapted to the constructivist-based learning model, Interpretation Construction (ICON) to draw up a storyboard and determining product specifications. The development phase done by developing a media IRVA using the camera to record video, voice recorder, as well as computer software Adobe Premiere (video editing program, integrate animation, voice narration and additions), Blender (a 3D animation program) and Swishmax (animation program for text). The implementation phase conducted with media ratings IRVA by 2 lecturers expert, feasibility studies by 3 subject teachers of Physics and the trial is limited to 10 high school students. Furthermore, the phase of the evaluation in the form of a revision of the product. Instruments used in the implementation phase is the assessment sheet of media with Likert scale, four level rating scale and the comment column. IRVA assessment by experts conducted by aspects of the content, pedagogic and media that have the criteria as presented in Table I. The data processing was performed data qualitative method so that it can show the feasibility of IRVA.

TABLE I. ASPECT AND CRITERIA FOR ASSESSING MEDIA IRVA

\begin{tabular}{|l|l|}
\hline Aspect & \multicolumn{1}{|c|}{ Criteria } \\
\hline Content & 1.The relevance of indicator and IRVA content \\
& 2.The correctnecc of Physics' concept \\
& $\begin{array}{l}\text { 3.The relevance of IRVA content with cognitive dimension } \\
\text { 4.The clearness of physical condition in an IRVA content }\end{array}$ \\
\hline Pedagogy & 5.The suitability of IRVA with ICON learning model stage \\
\cline { 2 - 2 } & 6.The IRVA can involve student to think \\
\cline { 2 - 2 } & 7.The IRVA can involve student to observe \\
\hline Media & 8.Video and animation exposure \\
\cline { 2 - 2 } & 9.Time duration \\
\cline { 2 - 2 } & 10.The clearness of text appearing \\
\cline { 2 - 2 } & 11.The fluency of narration \\
\cline { 2 - 2 } & 12.Music instrument usefulness \\
\cline { 2 - 2 } & 13.Navigation usefulness \\
\hline
\end{tabular}

\section{RESULTS AND DISCUSSION}

Results of the analysis phase shows that students are expected to apply the concept of Dynamics of Rotation in everyday events. In the Bloom taxonomy [15] this capability is included in the cognitive dimension of applying. IRVA media development can be done to help students for having analyzing ability, one level above the applying ability.

Media IRVA was designed to facilitate observation stage, cognitive conflict stage, and cognitive apprenticeship of the learning model ICON. The using of IRVA in the classroom learning will be operated by the teacher by using computers devices, LCD and speaker. IRVA will present the phenomenon of observation, variable changing for cognitive conflict and show the concept resume to strengthen cognitive learning stages. Students will write learning outcomes in a worksheet. IRVA product specification is a software with extension .exe that can be run on a PC or laptop.

Media development IRVA produce integrated video animation with opening view and main page IRVA media shown in Fig 1. 

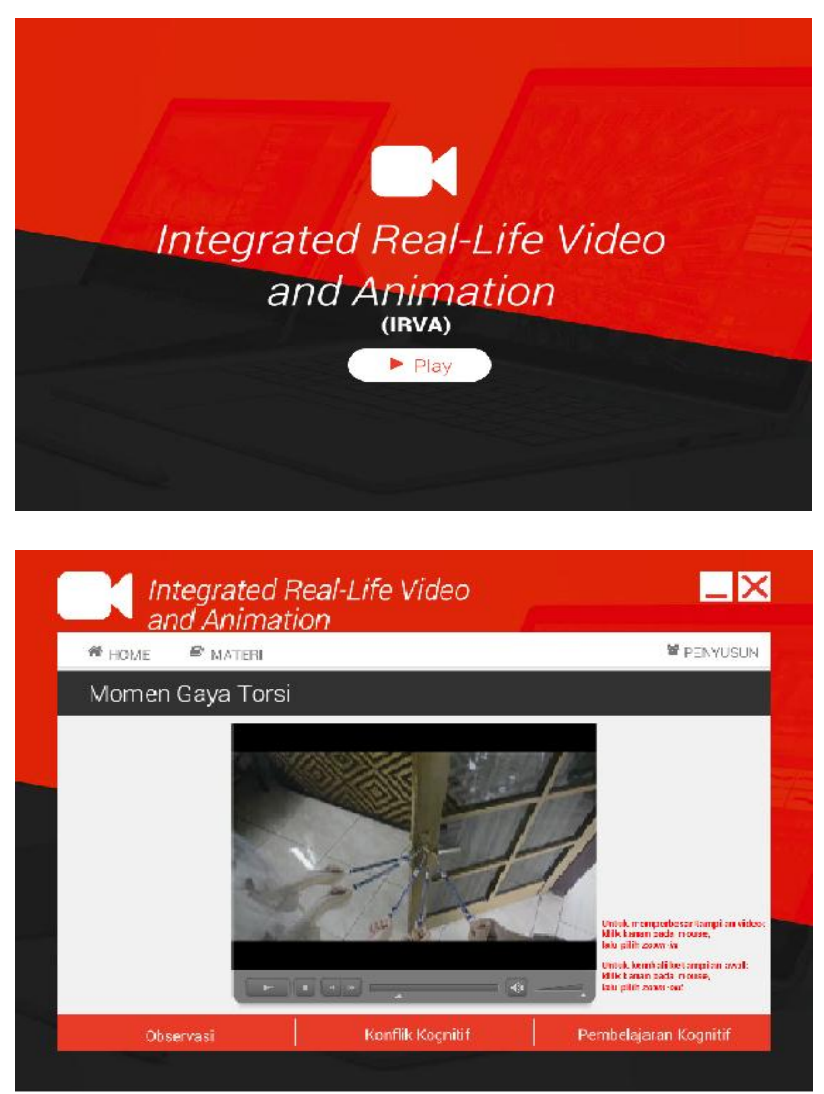

Fig. 1. The IRVA opening and main content appearance

The implementation of IRVA conducted on experts to give a judgement in terms of content, pedagogy and media. The assessment of content indicate that it is in conformity with the indicator IRVA learning materials. The accuracy and correctness of the concepts used are right and correct, as well as media content is in accordance with the dimensions of cognitive levels is expected that the ability to remembe , understand, apply and analyze. The intelligibility of IRVA is quite clear and related with the concept of Physics. Overall, the content aspect get an average of $96.87 \%$. This is consistent with the early stages of media design about the importance of determining the content of materials and examples of everyday phenomena relevant to students [16].

The average for pedagogy aspects up to $95.83 \%$ indicates that media IRVA is accordance with the stages of learning models of ICON, it can involve observation activity and can stimulate students to think. This is in line with the importance of prior knowledge of the students to learn concepts with meaningful [17]. Prior knowledge can be extracted through a process of observation and more thinking for getting cognitive conflict. IRVA that combined with ICON organized learning model will build an interconnected concepts, as Cakir concluded about an organized learning process. In terms of media, show that the lighting display video and animation as well as the clarity to see the text is good, it just needs to be improved for the resolution of the video or animation. Length of time for the video display is enough, it's not boring for too long impressions. Pronunciation of words in the narrative voice is clear and the volume was quite audible as well as musical accompaniment that was appropriate and do not interfere with the main narrative. IRVA navigation buttons on the media is already well. Overall, aspects of the media to get a mean value of $93.75 \%$. The advice given by the experts include: the addition of instructions to enlarge the video display/ zoom in and further development of media can be developed through the ability to create. Fig 2 shows the average score of each criterion on aspects of the content, pedagogy and media.

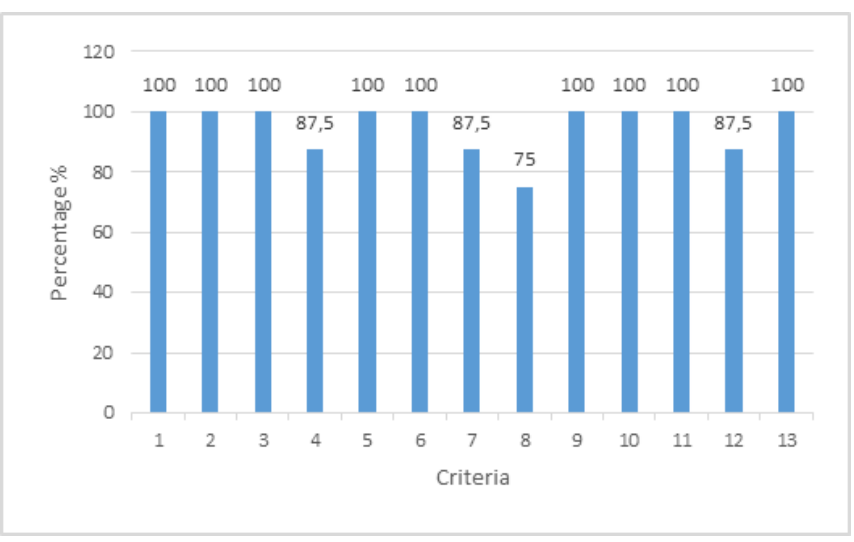

Fig. 2. The Average Score of Expert Judgement

After getting ratings and comments from experts, as well as the improvement of the advice given, the next implementation is a feasibility of IRVA conducted to three high school teacher of Physics. Assessment of the media IRVA done to respond to the statements assessment sheet with a choice : 4 for responses strongly agree, 3 to agree , 2 if not agree, and 1 if strongly disagree. From all aspects of the assessment, IRVA obtain an average value of $95.83 \%$. Fig 3 shows examples of Likert scale responses given by the teacher to IRVA.

TABLE II. LIKERT SCALE RESPONSES GIVEN BY TEACHER TO IRVA

\begin{tabular}{|c|c|c|c|c|}
\hline Statement & $\begin{array}{c}\text { Strongly } \\
\text { agree }\end{array}$ & Agree & $\begin{array}{c}\text { Not } \\
\text { agree }\end{array}$ & $\begin{array}{l}\text { Strongly } \\
\text { disagree }\end{array}$ \\
\hline $\begin{array}{l}\text { The correctness: } \\
\text { Concept delivered in } \\
\text { IRVA are related to the } \\
\text { concept that have been } \\
\text { deliver in a text book or } \\
\text { other source }\end{array}$ & $\sqrt{ }$ & & & \\
\hline $\begin{array}{l}\text { The deepness: } \\
\text { IRVA shows a detail } \\
\text { explanation }\end{array}$ & & $\sqrt{ }$ & & \\
\hline $\begin{array}{l}\text { Media element: } \\
\text { Video, animation and text } \\
\text { can be seen clearly }\end{array}$ & $\sqrt{ }$ & & & \\
\hline
\end{tabular}

Limited test was also conducted on 10 high school students who have studied the Rotational Dynamics. The results showed an average of $93.43 \%$ for all aspects of media IRVA. The advice given by the students are equipping IRVA with some exercises so that it can be used as an alternative learning resources individually at their homes. This suggestion can not 
be done yet because the development of IRVA is still focusing on the content and aim to support the learning process of ICON model in the classroom. In addition, the media development IRVA material Rotation Dynamics is also still intended to assist the construction of knowledge by students that can be observed directly by teachers in a relatively short time, so that the teachers can immediately provide feedback on the student worksheet.

\section{CONCLUSION}

The media development has been done by using ADDIE model produce an IRVA as a Physics learning materials of Rotational Dynamics topic. From the results of the assessment by experts in terms of content $(96.87 \%)$, pedagogy $(95.83 \%)$ and media $(93.75 \%)$ shows that the IRVA is feasible to use for learning activity in the classroom. Similarly, the results of feasibility test by teachers and limited testing by students, shows the average results of the responses were quite high (95.8\% and 93.43\%) which supports the results of the expert assessment. From the assessment result and some suggestions given, IRVA is revised and ready for use in a classroom learning activity, integrated with Interpretation Construction learning model.

\section{Acknowledgement}

Thank you for Winarto, M.Pd, a Physics multimedia lecturer from State University of Malang, for a fruitfull discussion and a warm guidance in developing the content of IRVA.

\section{References}

[1] J. Soland, L. S. Hamilton, and B. M. Stecher, "Measuring 21st Century Competencies Guidance for Educators 21 ST CENTURY COMPETENCIES," Asia Soc. Glob. Cities Educ. Netw., no. November, p. 68, 2013.

[2] T. Education and C. Skills, "21St Century Knowledge and," Education, no. September, p. 40, 2010.

[3] B. A. Adegoke, "EFFECT OF MULTIMEDIA INSTRUCTION ON SENIOR SECONDARY SCHOOL STUDENTS' ACHIEVEMENT IN PHYSICS,” Eur. J. Educ. Stud., vol. 3, no. 3, pp. 537-550, 2011.
[4] B. A. Adegoke, "Integrating animations, narratives and textual information for improving Physics learning.," Integr. animaciones, narraciones y textos para la Mejor. del Aprendiz. en Física., vol. 8, no. 2, pp. 725-748, 2010.

[5] K. Su and S. Yeh, "Effective Assessments of Integrated Animations to Explore College Students 'Physics Learning Performances," Procedia Soc. Behav. Sci., vol. 176, pp. 588-595, 2015.

[6] R. E. Mayer, R. Moreno, R. Brünken, J. L. Plass, D. Leutner, G. Convertino, J. Chen, B. Yost, Y.-S. Ryu, C. North, L. F. Laux, D. M. Lane, R. E. Mayer, and R. Moreno, "Nine Ways to Reduce Cognitive Load in Multimedia Learning," Educational Psychologist, vol. 38, no. 1. pp. 43-52, 2003.

[7] P. Norton and D. Hathaway, "Video Production as an Instructional Strategy : Content Learning and Teacher Practice," vol. 10, pp. 145-166, 2010.

[8] L. Bell and G. L. Bull, "Digital Video and Teaching," Contemp. Issues Technol. Teach. Educ., vol. 10, pp. 1-6, 2010.

[9] C. Chan and L. Robbins, "E-learning systems: promises and pitfalls," Acad. Psychiatry, no. December, 2006.

[10] M. Jasmy Abd Rahman, M. Arif Hj Ismail, and M. Nasir, "Development and evaluation of the effectiveness of computer-assisted physics instruction," Int. Educ. Stud., vol. 7, no. 13, pp. 14-22, 2014.

[11] Y. W. Astuti, "Bahan Ajar Fisika SMA dengan Pendekatan Multi Representasi," J. Pendidik. Sains, vol. 1, pp. 382-389, 2013.

[12] A. S. Fadaei, S. Daraei, and C. M. Ley, "Interactive multimedia related to real life, a model to teach physics in high school," vol. 1, no. 1, pp. 7-12, 2013.

[13] J. B. Black and R. O. McClintock, "An interpretation construction approach to constructivist design," Constr. Learn. Environ. case Stud. Instr. Des., pp. 25-31, 1995.

[14] C. C. Tsai, "The interpretation construstion design model for teaching science and its applications to Internet-based instruction in Taiwan," Int. J. Educ. Dev., vol. 21, no. 5, pp. 401-415, 2001.

[15] L. W. Anderson and D. R. Krathwohl, "A taxonomy for learning, teaching, and assessing: A revision of Bloom's taxonomy of educational objectives," Theory Pract., vol. Complete e, p. xxix, 352 p., 2001.

[16] C. Huang, "Designing high-quality interactive multimedia learning modules," Comput. Med. Imaging Graph., vol. 29, no. 2-3, pp. 223-233, 2005.

[17] M. Cakir, "Constructivist Approaches to Learning in Science and Their Implications for Science Pedagogy: A Literature Review," Int. J. Environ. Sci. Educ., vol. 3, no. 4, pp. 193-206, 2008. 